BENEFÍCIOS DA VITAMINA C NA PELE

Talicia Pereira de Araújo Mangela¹Adrianna Sousa dos Santos Martins²

1Bacharel em Biomedicina do Centro Universitário Luterano de Palmas

(CEULP/ULBRA), Palmas-TO, Brasil. taliciaa@hotmail.com

²Bacharel em Farmácia Generalista da Universidade de Gurupi (UNIRG), Gurupi-TO, Brasil.

Recebido em: 15/02/2021 - Aprovado em: 15/03/2021 - Publicado em: 30/03/2021 DOI: 10.18677/EnciBio_2021A4

\begin{abstract}
RESUMO
O ácido L-ascórbico, também conhecido como vitamina $\mathrm{C}$ oferece diversos benefícios ao organismo humano. É principalmente conhecida por atuar na melhora da imunidade, mas também por dar saúde para a pele. O ativo não é produzido pelo organismo, logo para adquirir os benefícios é preciso ingeri-la ou aplicá-la topicamente na pele. Uma das principais características dessa vitamina é a ação antioxidante. Além disso, também vai atuar como um clareador na pele, suavizar as linhas de expressão e neutralizar as ações dos radicais livres. Ou seja, é um ativo poderoso na busca pela pele perfeita, por isso é bastante consagrada na indústria farmacêutica pelo uso antioxidante ser bastante perceptível e eficaz. No presente trabalho os pesquisadores procuraram alcançar uma revisão narrativa da literatura sobre os benefícios da vitamina $\mathrm{C}$ na pele. Buscou-se identificar os vários benefícios oferecidos pela vitamina $\mathrm{C}$, descrever a atuação nas alterações decorrentes do envelhecimento cutâneo e pesquisar a ação antioxidante desta vitamina.
\end{abstract}

PALAVRAS-CHAVE: ácido ascórbico, envelhecimento cutâneo, vitamina c.

\title{
BENEFITS OF VITAMIN C ON SKIN
}

\begin{abstract}
The L-ascorbic acid, also known as vitamin C, offers several benefits to the human body. It is mainly known for acting on improving immunity, but also for giving health to the skin. The asset is not produced by the body, so to acquire the benefits it is necessary to ingest it or apply it topically to the skin. One of the main characteristics of this vitamin is its antioxidant action. In addition, it will also act as a skin lightener, smooth the expression lines and neutralize the actions of free radicals. In other words, it is a powerful asset in the search for perfect skin, which is why it is well established in the pharmaceutical industry because its antioxidant use is very noticeable and effective. In the present work, researchers seek to achieve a narrative review of the literature on the benefits of vitamin $C$ in the skin. We sought to identify the various benefits offered by vitamin $\mathrm{C}$, describe the role of changes resulting from skin aging and research the antioxidant action of this vitamin.
\end{abstract}

KEYWORDS: ascorbic acid, skin aging, vitamin c. 


\section{INTRODUÇÃO}

A pele com o tempo apresenta um leve desgaste natural, sendo afetada pela radiação ultravioleta. A prevenção do envelhecimento pode ser feita através da proteção da pele dos raios solares, com filtros solares, captação dos radicais livres através da atuação celular das vitaminas antioxidantes (SANTOS; OLIVEIRA, 2013).

Quando tem início o processo de envelhecimento, a derme apresenta-se mais fina, e a quantidade de colágeno torna-se reduzida. A exposição aos raios ultravioletas (RUV) acelera ainda mais essas alterações. Por atuar no estímulo da produção de fibras colágeno a partir da estimulação dos fibroblastos, mantendo a firmeza e a sustentação da epiderme e por apresentar efeito redutor de radicais livres, inibindo e neutralizando a ação desses radicais nas células. A vitamina $C$ tem sido utilizada como forma de reduzir os danos provocados pelos processos de envelhecimento (AZULAY et al., 2003; SILVA; FERRARI, 2011).

Sabe-se que existe uma correlação entre $O$ aumento de radicais livres e envelhecimento, portanto, carências de vitaminas como: $A, E, C$ e de oligoelementos como cobre, selênio e zinco podem acelerar o processo fisiológico do envelhecimento, principalmente o cutâneo (SANTOS; OLIVEIRA, 2013).

Para combater os efeitos dos RUV, a indústria cosmética vem investindo em formulações contendo vitamina $\mathrm{C}$, por ser eficaz no combate aos radicais livres, além de possuir ação despigmentante, em manchas senis e também por atuar na proteção e estimulação da síntese das proteínas estruturais da pele como o colágeno e elastina, responsáveis pela firmeza e elasticidade cutânea. Assim, essa vitamina, além de auxiliar na fotoproteção preventiva, também é considerada agente antiaging, por se tratar de um importante antioxidante. Dessa forma, o uso tópico tem se tornado importante forma de proteção à epiderme dos efeitos nocivos dos RUV a longo prazo (PUHL et al., 2018).

Entre os efeitos das RUV estão a depleção da vitamina $C$ da pele, alteração da síntese de DNA epidérmico e redução irreversível dos melanócitos, reduzindo assim a melanina, que é a proteção natural contra os raios, esses danos provocam a formação de rugas e manchas na pele (SANTOS; OLIVEIRA, 2013). O sistema antioxidante evita danos celulares, alterações proteicas e o desenvolvimento de patologias, essa defesa também protege a pele da formação dos radicais, estimulada pelos RUV. Com o passar do tempo esse potencial antioxidante natural vai reduzindo a função (BIANCHI; ANTUNES, 1999).

O ácido ascórbico (AA) apresenta grande capacidade de oxidação e por isso, a indústria cosmetológica tem investido também em seus derivados, para obter formulações com maior estabilidade química e, ainda, penetração cutânea em níveis eficazes, a fim de que não ocorra comprometimento das funções farmacodinâmicas. Apresenta-se de várias formas, dentre as quais as mais utilizadas em produtos cosméticos: nanoesferas (ácido ascórbico nanosferizado), talasferas (vitamina C englobada em microsferas de colágeno marinho recoberto por glicosaminoglicanas), ascorbosilane C (silício orgânico do ácido ascórbico), VC-PMG (fosfato de ascorbil magnésio), palmitato de ascorbila, VC-IP (tetraisopalmitato de ascorbila) (PUHL et al., 2018).

Atualmente, o uso de cosméticos para ajudar a melhorar a aparência da pele está em crescimento, visto que a estética, por meio de inovações na tecnologia, tem criado produtos com princípios ativos, capazes de atender a necessidade do consumidor. Diante do exposto, o presente estudo teve como objetivo identificar os vários benefícios oferecidos pela vitamina $C$ sobre a pele, descrever a atuação nas 
alterações decorrentes do envelhecimento cutâneo e pesquisar a ação antioxidante desta vitamina.

Foi realizada uma revisão narrativa da literatura, com buscas nas bases de dados: SciELO, Periódicos da CAPES e Google Acadêmico. Foram utilizados os descritores: ácido ascórbico, envelhecimento cutâneo, vitamina c. Foram incluídos apenas os artigos com disponibilidade de texto completo e originais.

\section{PELE}

A pele é o maior sistema orgânico do corpo humano, constitui em uma barreira protetora do organismo contra agressões do meio externo, é dividida em três camadas: epiderme, derme e hipoderme (SANTOS; OLIVEIRA, 2013). Ainda, age como órgão sensorial, regula a temperatura corpórea, regula a produção de vitamina D3, excreção de eletrólitos e outras substâncias, além de impedir a perda de água e de proteínas para o meio externo. Entretanto não se comporta como uma barreira totalmente impermeável, pois há um gradiente de penetração dependente da concentração e natureza da substância penetrante (TESTON et al., 2010).

A epiderme é responsável pela proteção e apresenta capacidade antioxidante maior que a derme, por exemplo, abriga a vitamina $C$, um composto essencial que sequestram radicais livres (PUHL et al., 2018). A pele desempenha várias funções: proteção, sensibilidade, termo regulação, função de secreção, absorção, respiração, reserva de lipídeos, produção de vitamina $\mathrm{D}$, cicatrização e função imunitária. A composição é de $70 \%$ de água, sais minerais, proteínas, lipídeos e glicídios (SANTOS; OLIVEIRA, 2013). Além disso, atua como uma barreira, evitando a perda de água e mantendo a hidratação, ajuda a manter a elasticidade e a firmeza da pele (PUHL et al., 2018).

A pele é prontamente visualizada e, portanto, a sua integridade é de grande importância psicológica e social, assim como fisiológica. Por estas razões, as alterações morfológicas, devido ao próprio processo de envelhecimento, e outras, aos efeitos cumulativos da exposição à luz solar ou outros fatores ambientais, que acompanham o envelhecimento da pele frequentemente afetam o indivíduo tanto na esfera funcional quanto psíquica, por isso o conhecimento da anatomia e fisiologia da pele é fundamental para a compreensão dos processos patológicos, para melhor indicação de métodos diagnósticos e terapêuticos (STRUTZEL et al., 2007; SANTOS et al., 2018).

\section{Envelhecimento cutâneo}

Envelhecer é natural e deve ser um processo sem traumas e com cuidados adequados. Mas, a qualidade do envelhecimento está relacionada diretamente com a qualidade de vida da pessoa que precisa adotar medidas profiláticas ou curativas, com a finalidade de conservar a qualidade de vida, retardando a influência ocasionada pelos fatores intrínsecos e extrínsecos que levam ao envelhecimento (SCHNEIDER; OLIVEIRA, 2004).

Mudanças nas características da pele humana durante o envelhecimento são frequentemente determinadas por forças ambientais ou extrínsecas, assim como por fatores intrínsecos, alguns relacionados as alterações no tecido conjuntivo da derme. Os sinais mais aparentes das alterações da pele senil são a atrofia, enrugamento, ptose e lassidão (ORIÁ et al., 2003).

O envelhecimento ocorre em todos os níveis celulares do organismo, sendo que cada tecido apresenta particularidades. É o resultado da danificação de moléculas, células e tecidos, os quais gradativamente perdem a capacidade de se 
adaptar ou de reparar um dano (GAVA; ZANONI, 2005). Durante a vida o indivíduo sofre diversas agressões por agentes físicos químicos ou biológicos, que podem levar ao aparecimento de patologias ou alterar o processo de envelhecimento (ORIÁ et al., 2003).

À medida que os indivíduos envelhecem, a pele perde uma de suas grandes propriedades: a elasticidade. Associado a isto, também ocorre perda de colágeno e reduz a hidratação, tornando-se seca por menor capacidade funcional das glândulas sudoríparas e sebáceas (STRUTZEL et al., 2007).

O envelhecimento pode ser classificado de duas formas básicas, dependendo de como ocorre: o intrínseco, ou cronológico, que evidencia uma pele mais fina, frágil, seca, com rugas finas e inelásticas e ocorre redução dos elementos presentes na epiderme e consequentemente da espessura, e o envelhecimento extrínseco, ou foto envelhecimento que está relacionado com a inevitável passagem do tempo e as condições que surgem ao longo do caminho, provocado principalmente por fatores externos que se sobrepõem ao envelhecimento intrínseco. Fatores como radiação ultravioleta, radicais livres, temperatura, tabaco e poluição, genética e cor da pele contribuem para o processo de envelhecimento (TESTON et al., 2010).

O foto envelhecimento é consequência do efeito da radiação ultravioleta do sol (UVA, UVB e UVC) sendo, portanto o principal responsável pelo envelhecimento cutâneo, pois a ação cumulativa provoca o envelhecimento extrínseco, alterando a pigmentação tornando-a irregular, provocando manchas e rugas profundas, além do ressecamento, pelo fato de ocasionar danos nas fibras de colágeno e elastina e estimulando a formação de radicais livres reativos que danificam a estrutura celular (TESTON et al., 2010).

Várias teorias foram e ainda estão sendo estudadas com a finalidade de explicar o processo de envelhecimento que abordam pontos em comum, as quais devem causar e acelerar os danos resultantes do avanço da idade. A maioria das teorias sobre o envelhecimento se baseiam mais em fatores genéticos, imunológicos e também ligados aos radicais livres, esta é a teoria mais aceita (GAVA; ZANONI, 2005; BERIGO et al., 2018).

\section{ANTIOXIDANTES}

Os antioxidantes são compostos químicos que podem prevenir ou diminuir os danos oxidativos de lipídios, proteínas e ácidos nucleicos causados por espécies de oxigênio reativo, que incluem os radicais livres, ou seja, os antioxidantes possuem a capacidade de reagir com os radicais livres e assim restringir os efeitos maléficos ao organismo (COUTO; CANNIATTI-BRAZACA, 2010).

Os antioxidantes atuam em diferentes níveis na proteção dos organismos. $O$ primeiro mecanismo de defesa contra os radicais livres é impedir a sua formação. Os antioxidantes são capazes de interceptar os radicais livres gerados pelo metabolismo celular ou por fontes exógenas, impedindo o ataque sobre os lipídeos, os aminoácidos das proteínas, a dupla ligação dos ácidos graxos poli-insaturados e as bases do DNA, evitando a formação de lesões e perda da integridade celular (CAVALARI; SANCHES, 2018).

Os radicais livres são produzidos naturalmente no organismo e são benéficos em caso de inflamações auxiliando no combate ao microrganismo. O problema está quando se tem uma produção exacerbada, fugindo do controle dos antioxidantes naturais que mantém a homeostase natural no organismo. Quando há limitação na disponibilidade de antioxidantes podem ocorrer lesões oxidativas de caráter 
cumulativo. Os antioxidantes são capazes de estabilizar ou desativar os radicais livres antes que ataquem os alvos biológicos nas células (VIDAL; FREITAS, 2015).

O oxigênio responsável pela manutenção da vida também pode gerar espécies reativas de oxigênio, os chamados de radicais livres, que atuam destruindo células e tecidos por meio da oxidação celular. Os radicais livres atuam no processo de envelhecimento, pois atingem direta e constantemente células e tecidos, os quais possuem ação acumulativa (GAVA; ZANONI, 2005).

Os radicais livres são moléculas altamente reativas que podem interferir em reações normais do organismo causando alterações. A reatividade se deve a instabilidade da molécula, por possuir elétrons desemparelhados (CAVALARI; SANCHES, 2018). O desequilíbrio entre moléculas oxidantes e antioxidantes, que resulta na indução de danos celulares, tem sido chamado de estresse oxidativo (CAVALARI; SANCHES, 2018).

Os radicais livres, qualquer átomo ou molécula, que contêm um ou mais elétrons não pareados em sua última camada eletrônica, são moléculas instáveis que perdem um elétron nas interações com outras moléculas que estão ao seu redor, e estão sendo cada vez mais reconhecidos como uma das principais causas do envelhecimento. Estes podem ser formados pela perda de um único elétron ou pelo ganho de um elétron de uma substância não radical. Podem também ser formados quando uma ligação covalente é quebrada e um elétron de cada um dos pares permanece em cada átomo (VANUCCHI et al., 1998; SCHNEIDER; OLIVEIRA, 2004; SANTOS; OLIVEIRA, 2013).

Quando não encontram nenhum outro radical livre para se ligar na tentativa de obter estabilidade, captam elétrons de outras moléculas saudáveis. A molécula que perdeu o elétron se transforma então em outro radical livre, iniciando-se uma reação em cadeia, que danificará muitas células, podendo ter caráter ilimitado, se não houver a intervenção dos antioxidantes. Este processo é chamado de oxidação, e provoca morte celular (SANTOS; OLIVEIRA, 2013).

Os radicais livres também participam da gênese do processo do envelhecimento, originando reações químicas, principalmente a oxidação. Tais reações desencadeiam processos nocivos ao organismo e são influenciadas por radiações, doenças, fumo e estresse (FARINATTI, 2002; SCHNEIDER; OLIVEIRA, 2004).

Quando dois radicais livres se encontram, as duas moléculas deixam de agir como radicais livres, mas quando um radical livre reage com uma molécula normal, imediatamente desencadeia uma reação em cadeia, formando um número sem fim de radicais livres, que só termina quando a extremidade radical que contém o elétron desemparelhado formar a ligação covalente com o elétron desemparelhado de outro radical. Assim, se os radicais primários produzidos não forem desativados imediatamente por enzimas ou moléculas antioxidantes, provocam danos nas macromoléculas biológicas como: acumulação destas moléculas nas células e tecidos, resultante de um aumento da produção de espécies reativas de oxigênio, ou de uma diminuição da capacidade antioxidante e/ou da velocidade de remoção e reparação das mesmas (MOTTA et al., 2004).

Ao longo dos anos, a concentração de radicais livres aumenta, e as defesas naturais antioxidantes falham, com isso 0 uso de compostos antioxidantes encontrados na dieta é um importante mecanismo de defesa contra os radicais livres. Algumas vitaminas atuam como antioxidantes também, a vitamina $\mathrm{C}$ é uma delas (BIANCHI; ANTUNES, 1999). 
Fries e Frasson (2010) asseguraram que o AA é um antioxidante que reage com diversos radicais livres e, por isso, seu uso em produtos cosméticos possibilita o suprimento de níveis que não seriam obtidos com o consumo de suplementação oral ou frutas. Essa suplementação de vitamina $C$ pode ser benéfica ou prejudicial, dependendo da situação em questão e da predisposição do sujeito (SANTOS et al., 2019).

Pesquisas demonstraram que a concentração de vitamina $C$ na pele é 20 a 30 vezes maior, quando utilizada topicamente, comparada à sua utilização oral, atua como um protetor biológico, diminuindo significativamente os danos provocados pela radiação UV (PUHL et al., 2018).

Os antioxidantes tópicos empregados nos cosméticos devem ser absorvidos pela pele e liberados para o tecido-alvo na forma ativa (FRIES; FRASSON, 2010). Com isso a indústria investiu bastante nos estudos de produtos antioxidantes a base da vitamina $\mathrm{C}$, buscando aprimorar as formulações, melhorar a estabilidade e o sensorial, já que este produto se mostrou bastante eficaz na utilização tópica contra o envelhecimento celular (VIDAL; FREITAS, 2015).

Nunes et al. (2018) concluíram que a aplicação tópica de vitaminas com poder antioxidante pode prevenir e tratar o processo de envelhecimento cutâneo, pois quando as substâncias ativas estão bem concentradas e são aplicadas na pele, têm a capacidade de fortalecer o epitélio e permitem uma ação farmacodinâmica através dos mecanismos de ação e propriedades terapêuticas conferindo efetividade do tratamento proposto.

\section{VITAMINA C}

As vitaminas são substâncias orgânicas de pequeno peso molecular, que agem em pequenas doses, sem qualquer valor energético intrínseco, além disso são essenciais para a manutenção das funções metabólicas dos seres humanos, atuam como cofatores de reações enzimáticas (ARANHA et al., 2000; SANTOS; OLIVEIRA, 2013).

Rodrigues et al. (2015) afirmaram, após estudo que, as vitaminas têm papel indispensável para que o metabolismo humano funcione corretamente, uma vez que depende das vitaminas para algumas funções. As vitaminas exercem duas funções principais, que são as coenzimas que auxiliam o catabolismo de algumas enzimas e também como antioxidantes contra os radicais livres, exercendo assim o papel de formadoras e protetoras de algumas funções dentro das células.

O médico Albert Szentgyorgyi, em 1928, conseguiu isolar a vitamina, dandoIhe o nome de ácido hexurônico. Ele descobriu ainda que a fórmula era $\mathrm{C} 6 \mathrm{H} 8 \mathrm{O} 6$. Em 1932, o isolamento da vitamina C em forma cristalina pura foi conseguido independentemente por dois grupos de pesquisadores. A estrutura química foi identificada e o produto sintetizado sob a forma fisiologicamente ativa pouco depois; em 1938 o ácido ascórbico foi oficialmente aceito como nome químico da vitamina C (ARANHA et al., 2000).

O ácido ascórbico corresponde a uma forma oxidada da glicose, C6H8O6 $(176,13 \mathrm{~g} / \mathrm{mol})$, sendo uma alfacetolactona de seis átomos de carbono, formando um anel lactona com cinco membros e um grupo enadiol bifuncional com um grupo carbonilo adjacente (VANNUCCHI; ROCHA, 2012).

A vitamina $C$ também chamada de ácido ascórbico (AA) é um composto hidrossolúvel, ou seja, é solúvel em meio aquoso, sendo absorvida pelos tecidos e levada pela corrente sanguínea até chegar ao tecido necessário, não necessitando assim do lipídio para ser absorvida. Além disso, é termolábil, sendo facilmente 
oxidado pelo calor e ocorre naturalmente em alimentos na forma reduzida de Lascórbico e seu produto de oxidação inicial é o ácido dehidroascórbico, ambos apresentando atividade vitamínica e são igualmente ativas, porém, a forma oxidada está muito menos difundida nas substâncias naturais (AZULAY et al., 2003).

Os seres humanos não sintetizam a vitamina $C$, sendo então obtida de fontes alimentares; porém, o transporte até a pele e a concentração da vitamina neste local são limitados. Para fim de suprir essa necessidade, é comum a utilização de produtos de aplicação tópica que contenham esse ativo (GARCIA et al., 2017). Os benefícios fisiológicos da vitamina $C$ na aplicação tópica na pele são diversos, tais como efeito anti-inflamatório, podendo ser usado em tratamento de dermatoses inflamatórias, doenças autoimunes e doenças fotossensibilizantes (VIDAL; FREITAS, 2015).

O AA funciona no interior do corpo humano, encaixando-se em ambos os lados da reação de óxido-redução, que acrescenta ou retira átomos de hidrogênio de uma molécula. Quando se oxida forma o ácido dehidroascórbico pela retirada, por agentes oxidantes, de dois átomos de hidrogênio. Reduz-se pelo acréscimo de dois átomos de hidrogênio, formando novamente o ácido ascórbico (ARANHA et al., 2000; PUHL et al., 2018).

As propriedades físico-químicas do AA são as seguintes: solubilidade aquosa $=0,3 \mathrm{~g} / \mathrm{ml}$, ponto de fusão $=190-192^{\circ} \mathrm{C}$, potencial redox-Eo $=0,166 \mathrm{~V}$ em pH 4,0, $\mathrm{pKa}=4,17$, pka2 = 11,57, absorção máxima $=245 \mathrm{~nm}(\mathrm{pH}$ ácido $)-265 \mathrm{~nm}(\mathrm{pH}$ neutro) (ARANHA et al., 2000). As características são: apresenta bom potencial redox, sendo bom antioxidante; é inócuo fisiologicamente e usado em sinergismo com seus derivados; solubilidade: insolúvel em óleos; por isto recorre-se aos seus derivados, principalmente os ésteres, como o palmitato de ascorbila; concentração usual: 0,01 - 0,05\%. (CHORILLI et al., 2007).

As características organolépticas da vitamina C são: uma substância cristalina, com sabor ácido, é insolúvel na maior parte dos solventes orgânicos. $\mathrm{Na}$ água, é solúvel na proporção de $1 \mathrm{~g}$ em $3 \mathrm{~mL}$. O calor, a exposição ao ar e o meio alcalino aceleram a oxidação desta vitamina, especialmente quando o alimento está em contato com o cobre, o ferro ou enzimas oxidativas (VIDAL; FREITAS, 2015).

O uso da vitamina $C$ tópica como um fotoprotetor foi estudado in vitro e in vivo, demonstrando seus efeitos na prevenção da queimadura solar em células e diminuindo o eritema pós-exposição tanto para as radiações UVA quanto UVB. A adição da vitamina tópica para qualquer protetor solar anti-RUVA ou RUVB mostrou melhor proteção solar que quando comparado ao uso do protetor solar isolado. Além disso, o uso desse ativo tópico nos produtos para uso "depois do sol" foi eficaz na remoção das espécies reativas induzidas pelo UV (AZULAY et al. 2003).

O AA é útil em tratamentos cujos objetivos sejam a prevenção ou diminuição dos efeitos nocivos da radiação UV bem como a melhora da pele afetada por distúrbios de hiperpigmentação, estrias ou eritema pós-laser (GARCIA et al., 2017). Puhl et al. (2018) asseguram que o ácido ascórbico tem efeito foto protetor na pele. Não age como um filtro solar por si só, uma vez que não absorve luz solar no espectro UV. Desde modo, o protetor solar tópico exerce um bloqueio externo contra a radiação do sol, pois age superficialmente. Ao combinar o uso do filtro solar com antioxidantes a proteção passa a ser interna, já que a ação se prolonga para as células. Enquanto a vitamina $C$ isoladamente pode conferir foto proteção, parece funcionar otimamente em conjunto com a vitamina $\mathrm{E}$.

Pesquisas demonstraram que o tratamento realizado com a vitamina $C$ tópica pode atuar como protetor biológico, diminuindo significativamente os danos 
provocados pelo RUV. Sendo assim, o AA é amplamente utilizado como ativo em formulações cosméticas, já que trata-se de uma substância que apresenta múltiplas funções o que proporciona excelentes resultados no tratamento das alterações cutâneas provocadas pelo envelhecimento (GUIRRO; GUIRRO, 2004).

O AA exerce, na fase aquosa, uma ação antioxidante sobre a pele, protegendo-a da ação dos radicais livres, que age diretamente auxiliando no retardo do envelhecimento celular, diminuindo, também, incidência de doenças degenerativas, como o câncer, as doenças cardiovasculares, inflamações, disfunções cerebrais e diversas outras. Além disso, o uso tópico dessa vitamina estimula por reações químicas no metabolismo a formação das fibras colágenas existentes em praticamente todos os tecidos do corpo humano (derme, cartilagem e ossos) e consequentemente a formação de novo tecido (AZULAY et al. 2003; SILVA; FERRARI, 2011; SANTOS; OLIVEIRA, 2013).

$A$ vitamina $C$ é considerada essencial à saúde do ser humano, entretanto, não é sintetizada pelo organismo. É uma molécula ácida, com forte atividade redutora, derivada de açúcares. Também é conhecida por sua propriedade anti-inflamatória, que age na diminuição da ativação do fator de transcrição nuclear responsável pela produção de citocinas pró-inflamatórias, e por proteger as células contra o estresse oxidativo mediante a doação de elétrons de modo sequencial, que neutraliza radicais livres. Além dessa vitamina, outras do complexo B são necessárias para produção de catalase extra. $O$ ácido ascórbico exerce papel fundamental no crescimento e reparação do tecido conectivo e na síntese de colágeno, pois é um cofator fundamental na hidroxilação da prolina e lisina, aminoácidos essenciais para estrutura, manutenção e função do colágeno, e glicosaminoglicanas, os quais são fundamentais para o tônus e firmeza cutânea (AZULAY et al., 2003; SANTOS; OLIVEIRA, 2013; GARCIA et al., 2017).

Segundo Azulay et al. (2003) essa catalisação permite a formação e estabilização do colágeno de tripla hélice e a secreção no espaço celular como procolágeno. A hidroxilação tem importância na biossíntese de colágeno, uma vez que regula a formação da tripla hélice, a excreção do procolágeno e o cross-linking do tropocolágeno. A vitamina $\mathrm{C}$ atua na prevenção da oxidação do ferro, protegendo as enzimas lisil e prolil hidroxilases da autoinativação, e regula a síntese de colágeno I e III pelos fibroblastos (PUHL et al., 2018).

Para que haja síntese adequada de colágeno é preciso sinergismo entre o AA e a ingesta de proteínas que vão fornecer aminoácidos que constituem o colágeno (PUHL et al., 2018). A vitamina $C$ desempenha papel importante no metabolismo da tirosina, dos carboidratos, do ferro, na síntese de lipídeos e proteínas, na resistência às infecções e na respiração celular (PUHL et al., 2018).

O AA apresenta efeitos fisiológicos na pele, dentre os quais podem ser citados: a inibição da melanogênese, resultando no clareamento de manchas na pele, proteção da síntese do colágeno atuando como um cofator nas reações de hidroxilação de proteína e lisina, importantes aminoácidos que promovem a formação de tripla-hélice das fibras de colágeno do tecido conjuntivo (DALCIN et al., 2003). Por causa da propriedade de estimular a síntese de colágeno, a vitamina $C$ em um tratamento tópico prolongado pode resultar na ativação da síntese de fibroblastos e diminuir as cicatrizes causadas pela idade, principalmente na região peri-orbital (VIDAL; FREITAS, 2015).

A vitamina $C$ é conhecida como agente inibidor da formação da melanina pela redução na formação da o-quinona e da melanina oxidada. Trata-se de uma substância antioxidante que age sinergicamente com a vitamina $E$ em uma série de 
passos oxidativos da síntese de melanina sendo, porém, muito instável e rapidamente oxidada em solução aquosa. Além disso, quando associada com a vitamina $E$, seu efeito sinérgico tem um bom desempenho na capacidade de combater danos causados pelos radicais livres. Quando a vitamina $\mathrm{E}$ reage com um radical livre, é danificada, a vitamina $C$ repara o dano permitindo que aquele continue sua atividade sequestrante. $O$ sinergismo entre as vitaminas proporciona uma boa proteção contra danos provocados pelo UVB. Portanto, a vitamina $\mathrm{C}$ parece bem melhor que a $E$ na proteção contra danos de UVA (PUHL et al., 2018).

A maioria dos fármacos que são utilizados no tratamento de problemas dermatológicos tem como local de ação os tecidos mais profundos da pele. Assim, o fármaco necessita permear o estrato córneo para chegar ao local de ação. Desse modo, a utilização desta via está limitada pela capacidade destes ultrapassarem a barreira da pele (MARTINS; VEIGA, 2002).

A técnica do microagulhamento pode ser utilizada como potencializadora da permeação de ativos, como a vitamina C. Quando há uma lesão na pele, a qual ocasiona cicatrização, ocorre o aumento da produção de colágeno, há também aumento na demanda por vitamina $C$, sendo assim, é necessário aumentar a quantidade de vitamina, tanto na dieta quanto no local da aplicação do tratamento (GARCIA et al., 2017).

Lima et al. (2013) observaram que o microagulhamento pode ser utilizado como condutor de ativos, como o retinol e a vitamina $\mathrm{C}$, para estímulo isolado: no rejuvenescimento da face, melhorando a coloração, a textura e o brilho da pele; no tratamento de flacidez e de rugas, favorecendo a produção de colágeno e proporcionando aumento de volume da área tratada; na correção de cicatrizes; e na melhoria de estrias recentes e antigas. Por se tratar de uma substância altamente instável, a permeação através do microagulhamento surge como uma alternativa, pois permite que maior quantidade do AA chegue às camadas da pele (GARCIA et al., 2017).

Dalcin et al. (2003) concluíram que a eficácia do tratamento à base de vitamina $\mathrm{C}$ e seus derivados em cosméticos e dermatológicos é comprovada na inibição da melanogênese, na síntese do colágeno e na ação antioxidante, o que ajuda a prevenir e a reverter principalmente o envelhecimento cutâneo. Além disso, formulações tópicas desta vitamina possuem elevada instabilidade; nesse caso, a síntese de derivados é uma alternativa, uma vez que estes possuem eficácia semelhante e são mais estáveis, o que garante mais benefícios clínicos.

Nos cosmecêuticos comercializados são encontradas três formas principais da vitamina C: ácido L-ascórbico, que é pouco estável; ascorbil-6- palmitato; e fosfato de ascorbil magnésio, o mais estável, sendo que a estabilidade da vitamina somente é alcançada em formulações aquosas em $\mathrm{pH}$ ácido. Além disso, o ácido ascórbico não permite associação com outros ativos (GARCIA et al., 2017).

Muitas formulações tópicas do AA são incapazes de penetrar no estrato córneo ou, em função de sua instabilidade, podem ser inativas e inúteis (GARCIA et al., 2017). Porém, estudos evidenciaram que o uso tópico pode ser formulado de maneira que a estabilização seja garantida, ocorrendo aumento da permeação (AZULAY et al., 2003). Esses estudos demonstraram que pode ser transportada através da epiderme, desde que seja formulada em níveis de $\mathrm{pH}$ menores que 3,5. Aplicações diárias durante cinco dias de formulações com $15 \%$ de vitamina C, a um $\mathrm{pH}$ de 3,2, aumentou os níveis desta vitamina em 20 vezes no tecido, onde ocorreu saturação após três dias. Com a pele saturada observou-se que o tempo de meiavida desse ativo foi de aproximadamente quatro dias (PUHL et al., 2018). 
Existem algumas variáveis que devem ser levadas em consideração na questão da aplicação e melhora da pele, tais como peso molecular, veículo, a porcentagem do derivado ascórbico viável que o ativo fornece à derme (PUHL et al., 2018). Num estudo duplo-cego, realizado por Dalcin et al. (2003) em pacientes com pele fotoenvelhecida, no qual se fez uso de creme de vitamina $\mathrm{C}$ a $5 \%$ no pescoço e antebraços, apresentou uma diminuição altamente significativa das pregas profundas. A histologia demonstrou reparo de tecido elástico, os autores sugeriram que a vitamina $C$ tópica teve influência positiva em todos os parâmetros da pele com lesão actínia.

Sandoval et al. (2015) realizaram um estudo, avaliando in vivo e in vitro, os ativos vitamina $\mathrm{C}$, manose e ácido hialurônico fragmentado, os quais apresentaram eficácia comprovada na redução de rugas, uniformização e hidratação, sendo que a ação associada ainda não havia sido descrita na literatura. Já Silva e Andreata (2017) realizaram um estudo quanto à aplicação da técnica de radiofrequência associada ao uso tópico de vitamina C pura a $10 \%$ e puderam observar benefícios quanto à redução de rugas e linhas de expressão, bem como melhora na qualidade geral da pele. A nanotecnologia envolvendo a vitamina $C$ possibilita que esta possa ter ação 10 vezes mais potente quando comparada à pura ou de forma livre (PUHL et al., 2018).

O AA em nanoesferas são cápsulas estáveis e liberadas em nível cutâneo que age nas camadas mais profundas da pele, chegando até a camada basal podendo então atuar como despigmentante da pele pela sua ação antioxidante e inibidora da tirosinase, age por um mecanismo redutor, revertendo à reação de oxidação, que convertem a DOPA em melanina, principalmente a conversão de DOPA em dopaquinona. A melanina, portanto não pode ser formada por ação da tirosinase até que toda a vitamina $\mathrm{C}$ seja oxidada. $\mathrm{O} \mathrm{pH}$ de estabilidade é 7.0. Utilizado em concentrações de 0,5 a 2\% (PUHL et al., 2018).

Outras formas de utilizar a vitamina $C$ no tratamento das alterações cutâneas decorrentes do envelhecimento são através do emprego de seus derivados, menciona-se o fosfato de ascorbil magnésio (FAM) e o palmitato de ascorbila (PA). O FAM caracteriza-se por liberar essa vitamina ao penetrar na epiderme, tornandose capaz de realizar as funções desta. Este derivado é conhecido por remover radicais livres e estimular a síntese do colágeno, sendo que o mesmo apresenta boa estabilidade em relação ao pH acima de 5, à luz e ao calor (PUHL et al., 2018). Já o PA é caracterizado por ser um derivado lipossolúvel que ao ser hidrolisado gera ácido palmítico e ácido ascórbico, sendo facilmente transportado para as células, atuando na remoção de radicais livres e na promoção da síntese do colágeno (FRIES; FRASSON, 2010).

A talasfera de vitamina $C$ é revestida em microesferas de colágeno marinho recoberta por glicosaminoglicanas. A Talasfera é a forma mais compatível dessa vitamina, aceita quase todas as associações e possui boa solubilidade em água. As fosfatases cutâneas reagem com a pele para liberar moléculas de vitamina $C$, liberando-a para a pele. As vantagens de encapsulação são a inibição da interação da vitamina com outros ativos; maior estabilidade; proteção contra oxidação; maior estabilidade ao calor e luz; aplicação cosmética ideal com melhor aspecto sensorial, sem a percepção de cristais (PUHL et al., 2018).

A vitamina C tópica, apesar de muito utilizada, é extremamente instável, principalmente quando veiculada em cremes e loções, oxidando-se rapidamente e perdendo seu efeito cosmético. O contato com a luz, o ar e alterações da temperatura acelera a degradação. Vidal e Freitas (2015) afirmaram que o grande 
desafio do uso tópico dessa vitamina é encontrar uma base galênica estável após a mistura, pois ela apresenta-se somente estável em formulação aquosa em pH ácido, não permitindo associação com outros ativos, sendo restrita sua ação na cosmética médica por ser pura. A formulação usual é de 10\%. Os derivados da vitamina C como Ascorbil Fosfato de Magnésio (VC-PMG), Ascorbosilane C, Talasferas de Vitamina C, Glicosferas de vitamina C e Éster de Vitamina C são bem estáveis (TESTON et al., 2010).

Salvador et al. (2016) realizaram uma pesquisa sobre o papel das embalagens na manutenção da estabilidade da vitamina $C$ e concluiram que as emulsões cosméticas que a contenham devem ter o material de embalagem cuidadosamente selecionado, sendo as melhores embalagens para manter a formulação estável, sem a redução da atividade, de acordo com este estudo, são as embalagens de alumínio mantidas a temperatura ambiente. Por outro lado, as embalagens de plástico leitoso são as menos adequadas para o envase desses produtos. Azulay et al. (2003) também afirmaram que as preparações dessa vitamina devem ser mantidas em recipientes herméticos e em embalagens resistentes à luz para evitar exposição aos raios UV ou ao ar.

\section{CONSIDERAÇÕES FINAIS}

Os efeitos da vitamina $\mathrm{C}$ e de seus derivados têm sido comprovados. Contudo, evitar exposições excessivas ao sol, ter uma alimentação balanceada, horas adequadas de sono e praticar exercícios físicos moderados são importantes para prevenir e retardar os sinais do envelhecimento cutâneo.

Ressalta-se que a ação do ácido ascórbico é potencializada dependendo da concentração e a via de administração, sendo melhor aproveitada topicamente, quando comparada com a utilização oral.

A vitamina C quando utilizada corretamente desempenha propriedade benéfica como a função despigmentante, antioxidante e estimula a colagênese. $\mathrm{Na}$ via tópica, pode atuar como protetor biológico diminuindo os danos provocados pelo RUV, por isso o mercado de cosméticos tem investido em produtos contendo este ativo nas formulações. Nessa perspectiva, cabe enfatizar a importância sobre o uso do ácido ascórbico na rotina de cada indivíduo.

\section{REFERÊNCIAS}

ARANHA, F. Q.; BARROS, Z. F.; MOURA, L. S. A.; GONÇALVES, M. C. R.; BARROS, J. C.; METRI, J. C.; SOUZA, M. S. O papel da vitamina C sobre as alterações orgânicas no idoso. Revista de nutrição, São Paulo, v.13, n. 2, p.89-97, 2000. Disponível em: https://www.scielo.br/scielo.php?script=sci_arttext\&pid=S141552732000000200003 DOI: https://doi.org/10.1590/S1415-52732000000200003

AZULAY, M. M.; de LACERDA, C. A. M.; PEREZ, M. A.; FILGUEIRA, A. L.; CUZZI, T. Vitamina C. Anais Brasileiros de Dermatologia, v. 78, n. 3, p. 265-274, 2003. Disponível em: https://doi.org/10.1590/S036505962003000300002 DOI: 10.1590/S0365-05962003000300002

BERIGO, T. G.; PEREIRA, C. B.; SILVA T. O. Benefícios do uso da vitamina A retinol, na prevenção e tratamento do envelhecimento cutâneo facial. Revista Terra e Cultura: cadernos de ensino e pesquisa. Centro Universitário Filadélfia. Londrina-PR, Estética e Cosmética Edição Especial, ano 34, n.67, p.152, 2018. 
Disponível em: https://docplayer.com.br/81643091-Ano-34-estetica-e-cosmetica-edespecial-2018.html

BIANCHI, M. L.; ANTUNES, L. M. G. Radicais livres e os principais antioxidantes da $\begin{array}{llllll}\text { dieta. Revista de } & \text { Nutrição, } & \text { v. } & 12 & \text { n. }\end{array}$ p.123-130, $1999 . \quad$ Disponível em: https://doi.org/10.1590/S1415-52731999000200001 DOI: $10.1590 / S 1415-$ 52731999000200001

CAVALARI, T. G. F.; SANCHES, R. A. Os efeitos da vitamina C. Revista Saúde em Foco, p. 749, 2018. Disponível em: http://portal.unisepe.com.br/unifia/wpcontent/uploads/sites/10001/2018/09/086_Os_efeitos_da_vitamina_C.pdf

CHORILLI, M.; LEONARDI, G. R.; SALGADO, H. R. N. Radicais livres e antioxidantes: conceitos fundamentais para aplicação em formulações farmacêuticas e cosméticas. Revista Brasileira de Farmácia, 88(3), p. 113 - 118, 2007. Disponível em: https://rbfarma.org.br/files/PAG_113a118_RADICAIS.pdf

COUTO, M. A. L.; CANNIATTI-BRAZACA, S. G. Quantificação de vitamina C e capacidade antioxidante de variedades cítricas. Ciência e Tecnologia de Alimentos, v.30, suppl.1, p.15-19, 2010. Disponível em: https://www.scielo.br/scielo.php?pid=S010120612010000500003\&script=sci_abstract\&tlng= DOI: https://doi.org/10.1590/S010120612010000500003

DALCIN, K. B.; SCHAFFAZICK, S. R.; GUTERRES, S. S. Vitamina C e seus derivados em produtos dermatológicos: aplicações e estabilidade. Caderno de Família, v. 19, n. 2, p. 69-79, 2003. Disponível em: https://www.lume.ufrgs.br/bitstream/handle/10183/19751/000397477.pdf?sequence= 1

FARINATTI, P. D. T. V. Teorias biológicas do envelhecimento: do genético ao estocástico. Revista Brasileira de Medicina do Esporte, v.8, n.4, pp.129-138, 2002. Disponível em: http://dx.doi.org/10.1590/S1517-86922002000400001 DOI: 10.1590/S1517-86922002000400001

FRIES, A. T.; FRASSON, A. P. Z. Avaliação da atividade antioxidante de cosméticos "anti-idade". Revista Contexto \& Saúde, v. 10 n. 19 p. 17, 2010. Disponível em: https://www.revistas.unijui.edu.br/index.php/contextoesaude/article/view/1474 DOI: https://doi.org/10.21527/2176-7114.2010.19.17-23

GARCIA, F. S.; LIMA, L. T.; BOMFIM, F. R. C. O uso da técnica de microagulhamento associada à vitamina $c$ no tratamento de rejuvenescimento facial. Revista Científica da FHO|UNIARARAS, v. 5, n. 1, 2017. Disponível em: http://www.uniararas.br/revistacientifica/_documentos/art.019-2017-2.pdf

GAVA, A. A.; ZANONI, J. N. Envelhecimento celular. Arquivos de Ciências da Saúde Unipar, Umuarama, v.9(1), jan./mar., 2005. Disponível em: https://www.revistas.unipar.br/index.php/saude/article/view/218 DOI: https://doi.org/10.25110/arqsaude.v9i1.2005.218 
GUIRRO, E.; GUIRRO R.; Fisioterapia Dermato-funcional. 3. ed. São Paulo: Editora Manole, 2004.

LIMA, E. V. A.; LIMA, M. A.; TAKANO, D. Microagulhamento: estudo experimental e classificação da injúria provocada. Surgical \& Cosmetic Dermatology, v. 5 n. 2 p. 110-114, 2013. Disponível em: http://www.loktal.com/assets/v5-microagulhamento-estudo-experimental-e-classificacao-da-injuria-provocada(1).pdf

MARTINS, M. R. F. M.; VEIGA, F. Promotores de Permeação para Liberação Transdérmica de Fármacos: Uma Nova Aplicação para Ciclodextrinas. Revista Brasileira de Ciências Farmacêuticas, v. 38, n. 1, 2002. Disponível em: https://www.scielo.br/pdf/rbcf/v38n1/v38n1a04.pdf

MOTTA, M. P.; FIGUEIREDO, P. A.; DUARTE, J. A. Teorias biológicas do envelhecimento. Revista Portuguesa de Ciências do Desporto, v.4, n.1, p.81-110, 2004. Disponível em: https://www.researchgate.net/publication /268354890_Teorias_biologicas_do_envelhecimento

NUNES, B. B. V.; FERREIRA, A. M.; CRUZ, F.; SILVA, T. O. Antioxidantes e suas contribuições no combate aos Radicais livres. Revista Terra e Cultura: cadernos de ensino e pesquisa. Centro Universitário Filadélfia. - Londrina-PR, Estética e Cosmética Edição Especial, ano 34, n.67, p.144, 2018. Disponível em: https://www.unifil.br/portal/images/pdf/documentos/revistas/revista-terra-

cultura/especial-2018-estetica.pdf

ORIÁ, R. B.; FERREIRA, F. V. A.; SANTANA, É. N.; FERNADES, M. R.; BRITO, G. A. C. Estudo das alterações relacionadas com a idade na pele humana, utilizando métodos de histo-morfometria e autoflorescência. Anais Brasileiro Dermatologia, Rio de Janeiro, 78(4):425-434, 2003. Disponível em: https://www.scielo.br/pdf/abd/v78n4/16901.pdf

PUHL, G. M. D.; da SILVA E.; FELLER, G.; ZIMMERMANN, C. E. A importância do ácido ascórbico no combate ao envelhecimento. Revista Saúde Integrada, v. 11 n. 22, 2018. 2 Disponível em: http://local.cnecsan.edu.br/revista/index.php/saude/article/view/585/531

RODRIGUES, A. P.; CARVALHO, E. F.; SILVA, J. D.; SILVA, T. E.; MAZETO, T. K. Vitaminas Hidrossolúveis. Revista Saberes, Rolim de Moura, v. 3, n. Esp. jul./dez., p. 72-82, 2015. Disponível em: https://facsaopaulo.edu.br/wpcontent/uploads/sites/16/2018/05/ed3especial/7.pdf

SALVADOR, M. P.; OSHIRO JUNIOR, J. A.; CHIARI-ANDRÉO, B. G. Influência do material de embalagem na estabilidade de formulação cosmética contendo vitamina C. Revista Brasileira Multidisciplinar - ReBraM, v. 19, n.2, 2016. Disponível em: https://www.revistarebram.com/index.php/revistauniara/article/view/412

DOI: https://doi.org/10.25061/2527-2675/ReBraM/2016.v19i2.412

SANDOVAL, M. H. L.; CAIXETA, C. M.; RIBEIRO, N. M. Avaliação in vivo e in vitro da eficácia de um produto com associação de vitamina $\mathrm{C}$, ácido hialurônico fragmentado e manose na prevenção do envelhecimento cutâneo. Surgical \& 
Cosmetic Dermatology, Sociedade Brasileira de Dermatologia, v. 7, núm. 1, p. 3744, 2015. Disponível em: https://www.redalyc.org/articulo.oa?id=265538320006

SANTOS, J. T.; KRUTZMANN, M. W.; BIERHALS, C. C.; FEKSA, L. R. Os efeitos da suplementação com vitamina C. Revista Conhecimento Online, a. 11, v. 1, jan./abr, 2019. Disponível em: https://periodicos.feevale.br/seer/index.php/revistaconhecimentoonline/article/view/1 187 DOI: https://doi.org/10.25112/rco.v1i0.1187

SANTOS, M. P.; OLIVEIRA, N. R. F. O papel das vitaminas antioxidantes na prevenção do envelhecimento cutâneo. Disciplinarum Scientia. Série: Ciências da Saúde, Santa Maria, v. 15, n. 1, p. 75-89, 2013. Disponível em: https://periodicos.ufn.edu.br/index.php/disciplinarumS/article/view/1067

SANTOS, R. P. D.; SILVA, T. O.; AMORESE, R. C. P.; PEREIRA, C. B. Utilização da vitamina $C$ na prevenção e tratamento do envelhecimento cutâneo. Revista Terra e Cultura: cadernos de ensino e pesquisa. Centro Universitário Filadélfia. Londrina-PR, Estética e Cosmética Edição Especial, ano 34, n.67, p.194, 2018. Disponível em: https://www.unifil.br/portal/images/pdf/documentos/revistas/revistaterra-cultura/especial-2018-estetica.pdf

SCHNEIDER, C. D.; OLIVEIRA, A. R. Radicais livres de oxigênio e exercício: mecanismos de formação e adaptação ao treinamento físico. Revista Brasileira de Medicina do Esporte, v.10, n.4, p.308-313, 2004. Disponível em: http://dx.doi.org/10.1590/S1517-86922004000400008 DOI: 10.1590/S151786922004000400008

SILVA, R, M. da; ANDREATA, M. F. G. Rejuvenescimento Facial: a eficácia da radiofrequência associada à vitamina $C$. Revista Maiêutica, Indaial, v. 1 , n. 01 , p. 55-73, 2017. Disponível em: https://189-016-006142.asselvi.edu.br/index.php/EIP/article/view/1825/913

SILVA, W. J. M.; FERRARI, C. K. B. Metabolismo mitocondrial, radicais livres e envelhecimento. Revista Brasileira de Geriatria e Gerontologia, v.14, n.3, pp.441451, 2011. Disponível em: https://doi.org/10.1590/S1809-98232011000300005 DOI: https://doi.org/10.1590/S1809-98232011000300005

STRUTZEL, E.; CABELLO, H.; QUEIROZ, L.; CíCERO, M. F. Análise dos fatores de risco para o envelhecimento da pele: aspectos gerais e nutricionais. Revista Brasileira de Nutrição Clínica, v.22, n.2, p. 139-45, 2007. Disponível em: https://docplayer.com.br/11524428-Analise-dos-fatores-de-risco-para-oenvelhecimento-da-pele-aspectos-gerais-e-nutricionais.html

TESTON, A. P.; NARDINO, D.; PIVATO, L. Envelhecimento cutâneo: teoria dos radicais livres e tratamentos visando a prevenção e o rejuvenescimento. Revista UNINGÁ review, v.1, n.1, 2010. Disponível em: http://revista.uninga.br/index.php/uningareviews/article/view/451

VANNUCCHI, H.; ROCHA, M. M. Funções Plenamente Reconhecidas de Nutrientes Ácido Ascórbico (Vitamina C). ILSI Brasil International Life Sciences Institute, 
São Paulo, 2012. Disponível em: https://ilsibrasil.org/publication/funcoesplenamente-reconhecidas/

VANUCCHI, H.; MOREIRA, E. A.; CUNHA, D. F. da; JUNQUEIRA-FRANCO, M. V. M.; BERNARDES, M. M.; JORDÃO-JR, A. A. Papel dos nutrientes na peroxidação lipídica e no sistema de defesa antioxidante. Revista da Faculdade de Medicina de Ribeirão Preto, v.31 n.1 p.31-44, 1998. Disponível em: http://www.revistas.usp.br/rmrp/article/view/7316

DOI: https://doi.org/10.11606/issn.2176-7262.v31i1p31-44

VIDAL, P. C. L.; FREITAS, G. Estudo da antioxidação celular através do uso da vitamina C. Revista UNINGÁ, v.21, n.1, p.60-64, Jan/Mar 2015. Disponível em: http://revista.uninga.br/index.php/uningareviews/article/view/1611 